\title{
Study on the Application of Zinc-zeolite in Cosmetic Toothpaste
}

\author{
Difang Zhao ${ }^{1, ~ *, ~ C h u n s h e n g ~} \mathrm{Xu}^{2, \text {, }}$ \\ ${ }^{1}$ Department of Chemical and Material Engineering, Hefei University, Hefei, China \\ ${ }^{2}$ Guangzhou Qiancai Cosmetic Co., Ltd., Guangzhou, China
}

\section{Email address:}

zdf6910@163.com (Difang Zhao),xcs6603@163.com (Chunsheng Xu)

*Corresponding author

\section{To cite this article:}

Difang Zhao, Chunsheng Xu. Study on the Application of Zinc-zeolite in Cosmetic Toothpaste. American Journal of Chemical Engineering. Vol. 7, No. 2, 2019, pp. 65-70. doi: 10.11648/j.ajche.20190702.12

Received: October 25, 2018; Accepted: June 26, 2019; Published: July 11, 2019

\begin{abstract}
Beauty toothpaste, which can whiten teeth and refresh breath, is becoming more and more popular in the market. This paper studies the feasibility of applying zinc zeolite in toothpaste, including the preparation method of zinc zeolite toothpaste, quality index test, bacteriostasis test, stain removal test and halitosis reduction test. The results show that the quality of zinc zeolite toothpaste meets the requirements of china national standards. The bacteriostasis rate of 5\% zinc zeolite toothpaste to Staphylococcus aureus and Escherichia coli can reach 99.9\%. Zinc zeolite toothpaste has obvious effect of removing stains and halitosis. The conclusion of this paper is that zinc zeolite toothpaste is a safe and effective cosmetic toothpaste, which can be produced in batches.
\end{abstract}

Keywords: Zinc Zeolite, Toothpaste, Bacteriostasis, Remove Stains, Remove Halitosis

\section{Introduction}

With China's entry into a well-off society, people are increasingly demanding the quality and function of toothpaste, which is conductive to whitening teeth and oral health, is gaining more and more popularity in the market [1-4]. For example, Darlie Super White Toothpaste, with high cleaning silicon (HCS) as the active ingredient, can whitening the teeth, Yunnan Baiyao Toothpaste, with Chinese medicine as the active ingredient, can inhibits harmful bacteria in the mouth and freshens the breath; Nice Nutritive Toothpaste, with vitamins as active ingredients, can nursing gums. These are the market's best performing star toothpaste. This paper introduced that natural inorganic antibacterial agent zinc zeolite were applied to toothpaste, make the toothpaste by reducing the tartar and dental calculus very well to whitening teeth, bring more beauty to life through inhibiting harmful bacteria to relieve gum inflammation, and through the excellent adsorption to remove bad breath. This kind of toothpaste can be called beauty toothpaste.

Zinc zeolite has the effect of antimicrobial and deodorization, is a cosmetics raw materials which included in INCI, mainly as the skin protectant composition such as the astringent (with hemostatic effect), skin conditioner, and the skin protectant. Toxicological studies have shown that half of the lethal dose $\left(\mathrm{LD}_{50}\right)$ of zinc zeolite with acute toxicity is more than $5,000 \mathrm{mg} / \mathrm{kg}$ (rat via the mouth), which is an actual non-toxic substance [5]. According to Agion Technologies Inc., zinc zeolite is mild to the skin, no irritation, no risk of mutagenicity, no risk of chromosomal aberration. Animal experiments showed that the feed containing $0.46 \%$ zinc zeolite for 8 consecutive weeks had no negative effect on the serum, liver and intestinal indicators of laying hens [6]. This indicates that zinc zeolite is a safe cosmetic ingredient and can be used in oral care products such as toothpaste.

Zinc zeolite can adsorb the negatively charged cell membrane of bacteria, and combined with the $\mathrm{SH}$ and $\mathrm{NH}_{2}$ in cell membrane protein, destruct the energy metabolism system and respiratory system of microbial cells, and lead to the blocked of the cell growth or death. Zinc Zeolites are structurally stable inorganic substances that do not decompose over time like organic matter. Organic preservatives, on the other hand, break down over time and lose their preservative effect. Therefore, the bactericidal and antimicrobial effects of zinc zeolite are generally more stable and lasting [5, 7-9]. Zinc zeolite has a good affinity for substances with polarizable molecules for it has a large surface area and has a great 
electrostatic attraction in its pores [10]. Therefore, zinc zeolite can also be used as adsorbent and desiccant. On the other hand, Zinc zeolite can absorb hydrogen sulfide gas and can replace activated carbon [5]. Hydrogen sulfide is a colorless gas with fetor and toxicity. It can dissolve in water and become hydrogen sulfuric acid. When heated, hydrogen sulfide escapes from water. Low concentration of hydrogen sulfide has an impact on the eyes, respiratory system and central nervous system, and is also the main factor causing bad breath.

In this paper, the application of zinc zeolite in toothpaste is introduced, including the physical and chemical indexes of zinc zeolite toothpaste, the test of bacteriostatic performance, the clinical test of removing stains effect, and the clinical test of reducing halitosis effect. Zinc zeolite toothpaste will have the advantages of natural, green, environmental protection. For china is rich in the stock of natural zeolite, high purity $(95 \%)$, good whiteness (85\%), and the low price [5], This study will provide the depth development of natural zeolite resources in new ways.

\section{Experiment}

\subsection{Main Reagents and Instruments}

Zinc zeolite, the samples are propagated by the powder materials science and engineering teaching and research office of Hefei University; Other ingredients for toothpaste; Staphylococcus aureus (ATCC 6538), Escherichia coli (8099), Guangdong institute of microbiology.

YGP5 vacuum paste making machine, Jiangsu Huaying Machinery Co., Ltd; Halimeter type breath meter, Interscan Instruments Inc.; SW- CJ-2FD single surface ultra-clean bench, Suzhou Purification Equipment Co., Ltd; SHP -100 biochemical thermostat incubator, Shanghai Hongdu Electric Technology Co., Ltd; GMSX -280 pressure steam sterilizer, Beijing Ever Bright Medical Instrument Co., LTD; Type 303 electro thermal thermostat incubator, Shanghai Xun Neng Electric Heating Equipment Co., Ltd; PHS -25 acid meter, Shanghai Electric Science Instrument Co., Ltd.

\subsection{The Experimental Method}

\subsubsection{Preparation of Zinc Zeolite Toothpaste}

The formula of toothpaste for test sample is formulated in table 1 .

Table 1. Experimental formula of Zinc Zeolite toothpaste.

\begin{tabular}{lll}
\hline Raw material & Quality requirements & w/\% \\
\hline Natural calcium carbonate & Toothpaste grade & 42 \\
Zinc zeolite (Zinc loads 6\%) & Toothpaste grade & 5 \\
Sorbitol & Toothpaste grade & 15 \\
Propylene glycol & Pharmaceutical grade & 8 \\
Sodium carboxymethyl cellulose & Toothpaste grade & 0.5 \\
Hydroxypropyl guar gum & Toothpaste grade & 0.7 \\
Pure water & Reverse osmosis & Add to 100 \\
Saccharin sodium & Food grade & 0.25 \\
Sodium pyrophosphate & Food grade & 0.6 \\
Sodium dodecyl sulfate & Toothpaste grade & 2.2 \\
Silica dioxide & Toothpaste grade & 3 \\
Flavor & Toothpaste grade & 1.2 \\
Methyl methacrylate & Food grade & 0.1 \\
\hline
\end{tabular}

Accurately weigh each raw material according to the formula in table 1. Add the sodium saccharin, Sodium pyrophosphate and methyl methacrylate and other water-soluble raw materials to the dispersing pot and dissolve them using the heat pure water, and then add the Sorbitol (pre-mixed 1). Add sodium carboxymethyl cellulose and hydroxypropyl guar gum to propylene glycol and stir in a dispersing for 20 minutes. This process requires downtime to check for dispersion (pre-mixing 2). Add natural calcium carbonate, zinc zeolite ( $6 \%$ zinc content), sodium dodecyl sulfate and silicon dioxide into the powder pot, start the disperser for 20 minutes, disperse evenly and reserve (pre-mixed 3). Flavor (pre-mixed 4). Start paste making machine and increase the vacuum level to $-0.08 \mathrm{MPa}$, then stop the vacuum pump. Open the feed valve, inhale the pre-mix 1, keep the vacuum at $-0.08 \mathrm{MPa}$. Start the high-speed mixer, slow scraper, and inhaled premixed 2, After evacuated to over $-0.095 \mathrm{MPa}$ for $30 \mathrm{~min}$, stop machine and test the physical and chemical indexes of the gum. After being qualified, continue inhaling premix 3 , keeping the vacuum to $-0.095 \mathrm{MPa}$ above and honogeneous emulsion for $25 \mathrm{~min}$ then add the primixed 4 , keeping the vacuum to $-0.095 \mathrm{MPa}$ above and homogeneous emulsion for $15 \mathrm{~min}$, and then get the paste.

\subsubsection{Determination the Quality of Zeolite Toothpaste}

The quality of toothpaste was determined by reference to China's national standard GB 8372-2008.

\subsubsection{Antibacterial Test of Zinc-zeolite Toothpaste}

The determination is according to the methods regulation of the 2.1.11.3.2 of the Ministry of Health of the People's Republic of China "technical standard for disinfection (2002 edition).

\subsubsection{Clinical Test on the Effect of Zinc-zeolite Toothpaste on Removing Stain}

\section{(i) The Test Objects}

Select the staff of Southern Medical University Zhujiang hospital and a community staff of Guangzhou Haizhu district as the test object.

\section{(ii) The Inclusion and Exclusion Criteria}

Included in the criteria: Has the problem of discoloration of teeth; Good health, and agree to cooperate with inspection on time; Promise to use the oral hygiene measures provided daily and no other toothpaste during the test period; No history of allergy to oral health care products.

Exclusion criteria: Teeth with endogenous discoloration; Chemical drugs are now used for a long time; Antibiotics, immune agents and mouthwash should be used during the test; Wear a denture or orthodontic appliance; The treatments of cleaning treatment, scraping treatment and dental filling etc. are carried out that affects the observation of indicators during the test period.

\section{(iii) The Test Samples}

The test samples were provided by Guangzhou Qiancai Cosmetics Co., LTD; The contrast sample toothpaste is Doctor 
Dental's ordinary toothpaste; The test sample toothpaste is the sample toothpaste made according to the formula in table 1; The appearance of consistent. The words 702 and 902 are marked respectively. The toothbrush is Doctor Dental's soft-bristled toothbrush.

\section{(iv) The Test Method}

(1) The test design: Double blind and random test method was used.

(2) The test indicators: By trained oral physicians in oral cavity, every subject to $33,32,31,41,42$ and 43 for indicators of teeth, respectively, and color to the area of the tooth surface discoloration by Lobene index of color grading score scoring method.

(3) The area score standard is: 1 - no spot exists; 2 - the spots should not exceed $1 / 3$ of the tooth surface; 3 - the spots should not exceed $2 / 3$ of the tooth surface; 4 - The spots is $2 / 3$ larger than the tooth surface.

(4) The color rating standard is: 1 - No stain exists; 2 - Light spots (Yellow or tan); 3 - Moderate chloasma (Medium brown); 4 - Severe color spots (dark brown or black).

(5) The test process: The dental plaque index of each subject was recorded and rechecked after 4 weeks of use of toothpaste.

(6) The test group: Those who met the inclusion criteria and exclusion criteria were selected and divided into 702 and 902 groups according to the random table. The two groups were basically the same in body condition, dental plaque severity, age and sex ratio.

\section{(v) The statistical Analysis}

In this test results, 4 weeks data comparison before and after using toothpaste for paired rank and inspection (Wilcoxon Signed Ranks Test) within the group, the set of data comparison using the non-matching rank and inspection (the Mann - Whitney Test) between the group.

\subsubsection{Clinical Trial of Zinc Zeolite Toothpaste for Reducing Halitosis}

\section{(i) The Research Objects}

The subjects were males who met the inclusion criteria and exclusion criteria and who had oral halitosis and who frequently smoked and drank alcohol. The crowd number is 20 people.

\section{(ii) The Test Samples}

The test samples are the same as the sample from a clinical trial on the efficacy of removing stain.

\section{(iii) The Test Instruments}

Halimeter type breath meter. The concentration of volatile sulfide (VSCs) in oral gas was measured by electrochemical thory as the indicators of the patient's breath level. Use ambient air to zero before use. The subjects breathe through their nose while taking measurements, open the mouth slightly, Set the Air collector mouth on the third of back of the tongue $0.5 \mathrm{~cm}$ above the junction, read the number value on the display. Repeat 3 times at a time and average the results.

\section{(iv) The Test Method}

(1) The test design: Double blind and random test method was used.

(2) There were 10 people in the experimental group and 10 people in the contrast group, squeeze the corresponding toothpaste on the standard toothbrush $2 \mathrm{~cm}$, and brush for $3 \mathrm{~min}$.

(3) The VSCs concentration in the oral cavity was measured for the first time before the subjects rinsed their teeth; VSCs concentration in the oral cavity was measured for the second time $5 \mathrm{~min}$ after brushing; VSCs concentration in the oral cavity was measured for the third time at $60 \mathrm{~min}$ after brushing. VSCs concentration in the mouth was measured for the fourth time at 120 min after brushing.

\section{(v) The Statistical Analysis}

Statistics of the changes of various indicators before and after the test were made separately. If the effect of the test group was significantly better than that of the negative contrast group, it indicates that the test product has anti - oral halitosis effect.

\subsubsection{Characterization of Microstructure of Zinc Zeolite}

An XRD analysis was performed to check the microstructure of zinc zeolite. The structure of the Al, Algraphene, and Al-MWNT samples were examined using a TD-3500 Dandong TongDa Diffractomer; Using K-alpha radiations from a fine-focus $\mathrm{Cu} \mathrm{X}$-ray tube. X-ray diffraction (XRD) scans were obtained for two-theta range $5 \sim 70 \circ$ at $0.1^{\circ}$ step, $10 \mathrm{~s} /$ point.

\section{Results and Discussion}

\subsection{Quality Index of Zinc Zeolite Toothpaste}

Table 2 shows the comparison between the quality index of zinc zeolite toothpaste and GB 8372-2008. It can be seen from table 2 that zinc-zeolite toothpaste has fully met the requirements of china national standards. At the same time, the sample toothpaste after 3 months of $45^{\circ} \mathrm{C}$ oven, and $-8^{\circ} \mathrm{C}$ refrigerator appraisal one month, there was no abnormality in the paste after restoring room temperature. This indicates that the formula can meet the requirement of mass production.

Table 2. The quality index of zinc-zeolite toothpaste and comparison with national standard.

\begin{tabular}{lll}
\hline Project & $\begin{array}{l}\text { zinc-zeolite } \\
\text { toothpaste }\end{array}$ & $\begin{array}{l}\text { The national standard, GB } \\
\mathbf{8 3 7 2 - 2 0 0 8}\end{array}$ \\
\hline $\mathrm{pH}$ & 8.4 & $\begin{array}{l}5.0-10.0 \\
\text { glass free from scratch }\end{array}$ \\
Paste & $\begin{array}{l}\text { no scratch } \\
\text { homogeneous, No } \\
\text { foreign matter }\end{array}$ & $\begin{array}{l}\text { homogeneous, No foreign } \\
\text { matter } \\
\text { The paste does not overflow the } \\
\text { tube mouth, does not separate out } \\
\text { the liquid, the fragarance and the } \\
\text { color is normal }\end{array}$ \\
Stability & no abnormal & 500 \\
\hline $\begin{array}{l}\text { Total number of } \\
\text { colonies } /\left(\mathrm{CFU} \cdot \mathrm{g}^{-1}\right)\end{array}$ & $\leqq 10$ &
\end{tabular}




\begin{tabular}{lll}
\hline Project & $\begin{array}{l}\text { zinc-zeolite } \\
\text { toothpaste }\end{array}$ & $\begin{array}{l}\text { The national standard, GB } \\
\mathbf{8 3 7 2 - 2 0 0 8}\end{array}$ \\
\hline $\begin{array}{l}\text { Total number of mold } \\
\text { and yeast } /\left(\mathrm{CFU} \cdot \mathrm{g}^{-1}\right)\end{array}$ & $\leqq 10$ & 100 \\
$\begin{array}{l}\text { Fecal coliforms } \\
\text { Pseudomonas }\end{array}$ & did not check out & may not be detected \\
$\begin{array}{l}\text { aeruginosa } \\
\text { Staphylococcus aureus }\end{array}$ & did not check out & may not be detected \\
$\begin{array}{l}\text { Pb content }\left(\mathrm{mg} \cdot \mathrm{kg}^{-1}\right) \\
\text { As content }\left(\mathrm{mg}^{-1} \mathrm{~kg}^{-1}\right)\end{array}$ & $\leqq 1$ & may not be detected \\
\hline
\end{tabular}

\subsection{Antibacterial Effect of Zinc Zeolite Toothpaste}

The test results of antibacterial effect of zinc zeolite toothpaste are shown in table 3 . According to literature [5, 11], the Staphylococcus aureus and Escherichia coli antibacterial rate can reach $99.9 \%$ when the zinc zeolite mass fraction exceeds $2 \%$. The quality score of the sample toothpaste zinc zeolite is $5 \%$. Table 3 shows that the test marker toothpaste has good bacteriostatic effect on E. coli and S. aureus.

Table 3. Test result of bacteriostatic effect of zinc zeolite toothpaste.

\begin{tabular}{|c|c|c|c|c|c|}
\hline \multirow{2}{*}{$\begin{array}{l}\text { Concentration and } \\
\text { Treatment time }\end{array}$} & \multirow{2}{*}{$\begin{array}{l}\text { Tested } \\
\text { microorganism }\end{array}$} & \multirow{2}{*}{$\begin{array}{l}\text { Serial } \\
\text { number }\end{array}$} & \multicolumn{2}{|c|}{ Viable bacteriagroup/(CFU $\left.\cdot \mathrm{g}^{-1}\right)$} & \multirow{2}{*}{$\begin{array}{l}\text { Bacteriostatic } \\
\text { Rate } / \%\end{array}$} \\
\hline & & & in comparison & in experimental & \\
\hline \multirow{5}{*}{$\begin{array}{l}3 \mathrm{~min} \\
\text { The original solution }\end{array}$} & \multirow{3}{*}{$\begin{array}{l}\text { E.coli } \\
(8099)\end{array}$} & 1 & $5.2 \times 10^{4}$ & $<10$ & 99.98 \\
\hline & & 2 & $5.1 \times 10^{4}$ & $<10$ & 99.98 \\
\hline & & 3 & $5.6 \times 10^{4}$ & $<10$ & 99.98 \\
\hline & \multirow{2}{*}{$\begin{array}{l}\text { S.Aureus } \\
\text { (ATCC 6538) }\end{array}$} & 1 & $4.1 \times 10^{4}$ & $<10$ & 99.97 \\
\hline & & 2 & $4.3 \times 10^{4}$ & $<10$ & 99.97 \\
\hline
\end{tabular}

\subsection{Zinc-zeolite Toothpaste Stain Removal Effect}

Fifty people were selected to complete the experiment. Forty-four men and six women, aged 20 to 58, were divided into two groups.

\subsubsection{The Results of Comparison Between the Two Groups of Subjects Before and After the Test on the Change of Lobene Color Spot Index Area Grading Score}

After used the 702 for 4 weeks, the subjects had an average Lobene stain Index area classification score from 15.84 reduced to 15.24 , By rank sum test, $\mathrm{Z}=-2.543, \mathrm{P}=0.011>$ 0.01 . It can be considered that there is no statistically significance of difference in the area of the subjects' index plaque before and after using sample 702. It was suggested that the area of the subjects' dental plaque did not change significantly after sample 702 was used.

After used the 902 for 4 weeks, the subjects had an average Lobene stain Index area classification score from 15. 92 reduced to 14.34 , By rank sum test, $\mathrm{Z}=-3.034, \mathrm{P}=0.002<$ 0.01 . It can be considered that there is statistically significance of difference in the area of the subjects' index plaque before and after using sample 902. It was suggested that the area of the subjects' dental plaque had changed significantly after sample 902 was used.

\subsubsection{The Changed Scoring Results of Lobene Color Spot Index Color Grading Before and After the Two Groups of Subjects}

After used the 702 for 4 weeks, the subjects had an average Lobene stain Index color classification score from 12.32 reduced to 10.94 , By rank sum test, $\mathrm{Z}=-1.087, \mathrm{P}=0.227>$ 0.01 . It can be considered that there is no statistically significance of difference in the color of the subjects' index plaque before and after using sample 702. It was suggested that the color of the subjects' dental plaque did not change significantly after sample 702 was used.

After used the 902 for 4 weeks, the subjects had an average
Lobene stain Index color classification score from 12. 08 reduced to 11.68 , By rank sum test, $\mathrm{Z}=-1.194, \mathrm{P}=0.232>$ 0.01 . It can be considered that there is no statistically significance of difference in the color of the subjects' index plaque before and after using sample 902. It was suggested that the color of the subjects' dental plaque did not change significantly after sample 902 was used.

\subsubsection{Four Weeks After the Use of 702 and 902 Samples, the Difference Between the Two Groups of Indicators Lobene}

Color spot index area grading score and the difference before use was compared. By rank sum test, $\mathrm{Z}=-1.050, \mathrm{P}=$ $0.294>0.01$. It can be considered that there is no statistically significance of difference in the area of the subjects' index plaque before and after using sample 702 and 902 between the two groups. It was suggested that the area of the subjects' dental plaque did not change significantly after sample 702 and 902 were used between the two groups.

\subsubsection{The Results of Comparison Between the Two Groups of Subjects Before and After the Test on the Change of Lobene Color Spot Index Color Grading Score}

Four weeks after the use of 702 and 902 samples, the difference between the two groups of indicators Lobene color spot index color grading score and the difference before use was compared. By rank sum test, $\mathrm{Z}=-0.385, \mathrm{P}=0.700>0.01$. It can be considered that there is no statistically significance of difference in the color of the subjects' index plaque before and after using sample 702 and 902 between the two groups. It was suggested that the color of the subjects' dental plaque did not change significantly after sample 702 and 902 were used between the two groups.

To sum up, in this study, after 902 and 4 weeks of use of the sample, the area of the subject's target tooth color spot was significantly improved, which had a significant decoloring effect on the teeth. 


\subsection{The Effect of Zinc Zeolite Toothpaste Reduces Bad Breath}

The average VSCs concentration of the test group and the contrast group before and after brushing is shown in table 4. It Can be seen from table 4 that after using the toothpaste, the oral odor value in each group has a certain decline. It shows that it can keep fresh breath after using toothpaste. But zinc-zeolite toothpaste can decline to a certain extent of the oral odor value, $2 \mathrm{~h}$ after oral can still keep pure and fresh feeling, However, ordinary toothpaste less decline on the oral odor value, $2 \mathrm{~h}$ after oral odor value of basic return to original state.

Table 4. Effect of Zinc-Zeolite toothpaste on reducing halitosis.

\begin{tabular}{|c|c|c|c|c|}
\hline \multirow{3}{*}{ Group } & \multicolumn{4}{|l|}{ W (VSCs) / ( $\left.\mu \mathrm{g} \cdot \mathrm{kg}^{-1}\right)$} \\
\hline & \multirow{2}{*}{$\begin{array}{l}\text { Oral odor before brushing } \\
\text { teeth }\end{array}$} & \multicolumn{3}{|c|}{ after brushing teeth } \\
\hline & & Oral odor $5 \mathrm{~min}$ & Oral odor $60 \mathrm{~min}$ & Oral odor $120 \mathrm{~min}$ \\
\hline The experimental group & 502 & 383 & 402 & 454 \\
\hline The contrast group & 512 & 467 & 471 & 513 \\
\hline
\end{tabular}

\subsection{Microcrystalline Structure of Zinc Zeolite Inorganic Anti-bacterial Agent}

$\mathrm{X}$ - ray diffraction (XRD) was performed on the microcrystalline structure of zinc zeolite inorganic antibacterial agents. The results are shown below. It can be seen from the figure 1 that the samples have major zeolite peaks at $\sim 7.08^{\circ}, \sim 10.04^{\circ}, \sim 12.34^{\circ}, \sim 15.98^{\circ}, \sim 21.54^{\circ}, \sim 23.86^{\circ}$, $\sim 27^{\circ}, \sim 29.82^{\circ}, \sim 34.06^{\circ}, \sim 52.48^{\circ}$ and $\sim 68.5^{\circ}$. Despite only having $\sim 6 \mathrm{wt} \%$ zinc loaded on the zinc-zeolite inorganic anti-bacterial agent, the peaks for zinc are seen at $\sim 35.7^{\circ}$, $\sim 42.4^{\circ}$, and $\sim 54.1^{\circ}$ two theta degree.

A conclusion can be drawn from this that the zinc-zeolite maintain the microcrystalline structure of zeolites and the Zinc is loaded on the surface of zeolite or in the pore structure.

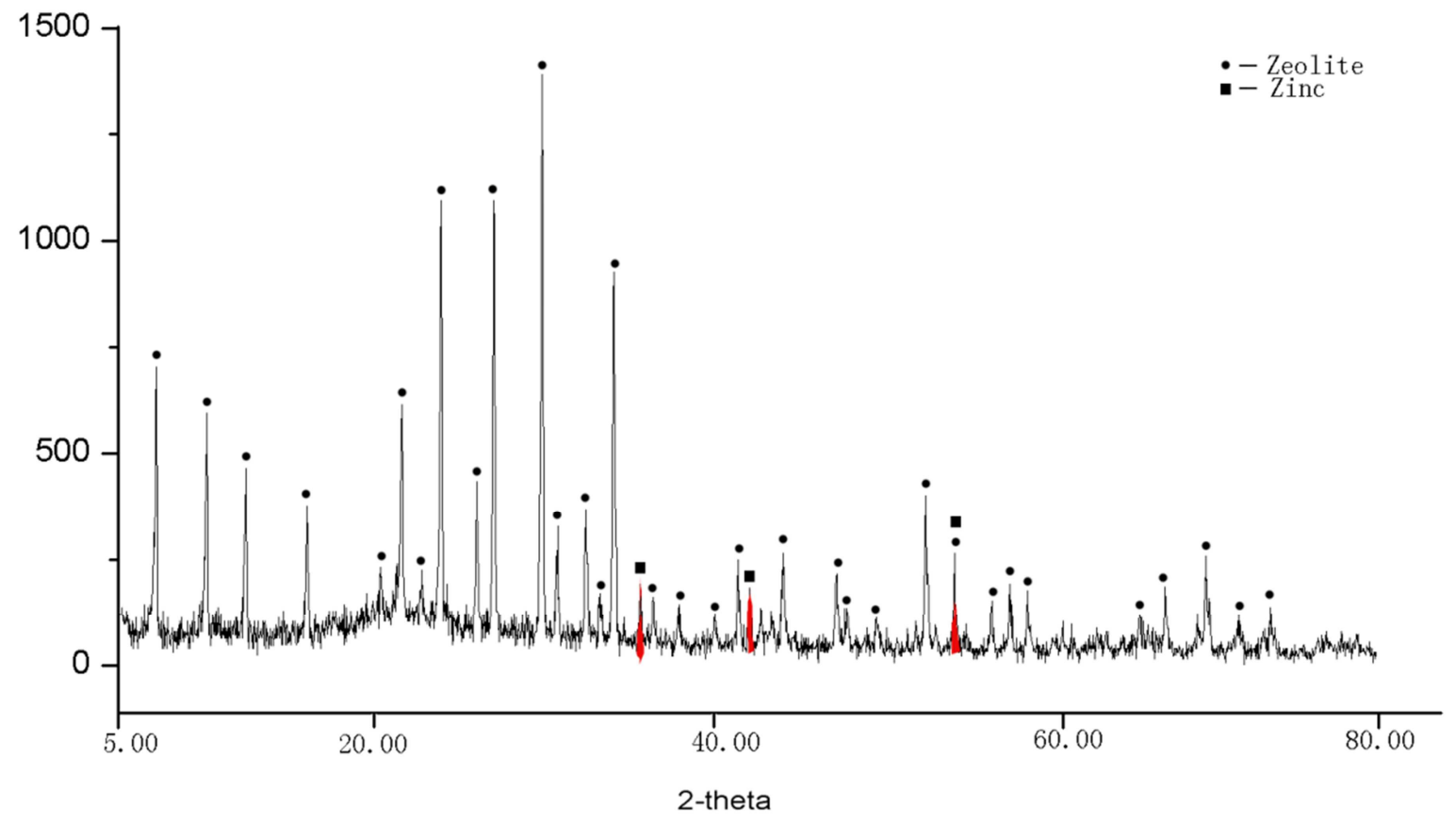

Figure 1. X-ray diffraction of zinc-zeolite inorganic antibacterial agent.

\section{Summary}

Zinc zeolite is a safe inorganic antibacterial agent with antibacterial and deodorizing effects. It can be used in toothpaste and other personal care products. The results show that the quality of zinc zeolite toothpaste conforms to the china national standard. The toothpaste samples with $5 \%$ mass fraction of zinc zeolite can reach $99.9 \%$ antibacterial rate to staphylococcus aureus and Escherichia coli. Zinc-zeolite toothpaste can reduce the area of the subjects' teeth color spots significantly, and has a significant effect on removing stains. It can also significantly reduce the concentration of hydrogen sulfide gas in the subjects' oral cavity, and has a significant and lasting effect on deodorization.

\section{References}

[1] Feng Dehou, Li Yiping. Hydroxyapatite and cosmetic toothpaste [J]. Toothpaste Industry, 2002 (4): 27-30 (in Chinese).

[2] Huang Gangway, Luo Zhe. Research on whitening toothpaste [J]. Oral Care Products Industry, 2010 (6): 18-20 (in Chinese). 
[3] Chen Minshan, Jang Shan, Gao Yan. Development of whitening morning and evening toothpaste and research on whitening effect $[\mathrm{J}]$. Oral Care Products Industry, 2014 (5): 19-22 (in Chinese).

[4] Fei Zhenyu, Zhang Hu. Development of fresh breath toothpaste [J]. Oral Care Products Industry, 2014 (6): 18-20 (in Chinese).

[5] Ding Hao, Deng Yanxi, Xu Xia, etc. Preparation and properties of inorganic antibacterial agents containing zinc-bearing zeolite [J]. Functional materials, 2007, 38 (5): 3437-3439 (in Chinese).

[6] Li Ping, Tang Zhigang, Li Linfeng, etc. Effects of zinc-loaded zeolite on production performance, serum hormone level and antioxidant function of laying hens [J]. China journal of grain and oil, 201530 (3): 94-100 (in Chinese).

[7] Xu Xia, Cao Xinsheng, Peng Hongjun. Preparation of inorganic antibacterial agent from natural zeolite and its application in building materials [J]. China building materials technology, 2006 (3): 11-118 (in Chinese).
[8] Chen, SJ, Popovich, J, Iannuzo, N, etc. Silver-Ion-Exchanged Nanostructured Zeolite X as Antibacterial Agent with Superior Ion Release Kinetics and Efficacy against Methicillin-Resistant Staphylococcus aureus [J]. Acs Applied Materals \& Interfaces. 2017, 45 (9): 39271-39282.

[9] Dolic, MB, Rajakovic-Ognjanovic, VN, Strbac, SB, etc. Natural sorbents modified by divalent $\mathrm{Cu} 2+-$ and $\mathrm{Zn} 2+-$ ions and their corresponding antimicrobial activity $[\mathrm{J}]$. New Biotechnology (A) [J]. 2017, 3 (39): 150-159.

[10] Zavareh, S, Farrokhzad, Z, Darvishi, F. Modification of zeolite $4 \mathrm{~A}$ for use as an adsorbent for glyphosate and as an antibacterial agent for water [J]. Ecotoxicology and Enveronmental Safety. 2018, 2, 43 (155): 1-8.

[11] Lisa, EL, Carac, G, Barbu, V, etc. The Synergistic Antioxidant Effect and Antimicrobial Efficacity of Propolis, Myrrh and Chlorhexidine as Beneficial Toothpaste Components [J]. Revista de Chimie, 2017, 9 (68): 2060-2065. 